\title{
Socioeconomic Inequalities in Visits to the Dentist to Receive Professionally Applied Topical Fluoride in a Developing Country
}

\author{
Miriam Del Socorro Herrera ${ }^{1}$, Carlo Eduardo Medina-Solís ${ }^{2,3, *,+}$ (D), \\ América Patricia Pontigo-Loyola ${ }^{2}$, Rubén de la Rosa-Santillana ${ }^{2}$, Leticia Ávila-Burgos ${ }^{4}$, \\ Rogelio José Scougall-Vilchis ${ }^{3}$ (D) , Sonia Márquez-Rodríguez ${ }^{2}$, Mirna Minaya-Sánchez ${ }^{5}$ and \\ Alejandro José Casanova-Rosado ${ }^{5}$ \\ 1 Faculty of Dentistry of National Autonomous, University of Nicaragua, León 21000, Nicaragua; \\ miriam.sherrera@yahoo.com \\ 2 Academic Area of Dentistry of Health Sciences Institute at Autonomous, University of Hidalgo State, \\ Pachuca 42039, Mexico; americap@uaeh.edu.mx (A.P.P.-L.); cdrubendelarosa@hotmail.com (R.d.1.R.-S.); \\ cdsoniamr@hotmail.com (S.M.-R.) \\ 3 Advanced Studies and Research Center in Dentistry "Keisaburo Miyata" of Faculty of Dentistry at \\ Autonomous, University State of Mexico, Toluca 50000, Mexico; rogelio_scougall@hotmail.com \\ 4 Health Systems Research Centre at National Institute of Public Health, Cuernavaca 62100, Mexico; \\ leticia.avila@insp.mx \\ 5 Faculty of Dentistry of Autonomous, University of Campeche, Campeche 24039, Mexico; \\ miminaya@hotmail.com (M.M.-S.); ajcasano@uacam.mx (A.J.C.-R.) \\ * Correspondence: cemedinas@yahoo.com \\ † Current address: Avenida Álamo \# 204, Fraccionamiento Paseo de los Solares, Colonia Santiago Tlapacoya, \\ CP. 42113, Pachuca de Soto, Hidalgo, Mexico.
}

Received: 17 July 2017; Accepted: 5 August 2017; Published: 11 August 2017

\begin{abstract}
Objective: To determine the frequency and associated factors of visits to the dentist in the last year by Nicaraguan schoolchildren to receive professionally applied topical fluoride (PATF). Material and Methods: A cross-sectional study was designed in children from public schools in the city of León, Nicaragua, were included. A series of socioeconomic, sociodemographic, and behavioural variables were collected through a questionnaire. The dependent variable was the visit to the dentist to receive professionally applied topical fluoride in the last year, which was dichotomised as (0) Did not receive PATF and (1) Yes received PATF. In the statistical analysis, binary logistic regression was used. Results: The mean age of the students included was 9 years, and $49.9 \%$ were girls. The prevalence of visits to the dentist in the last year to receive PATF was 3.1\%. In the multivariate model, the associated characteristics $(p<0.05)$ were: female $(\mathrm{OR}=2.73,95 \% \mathrm{CI}=1.34-4.50)$; the positive attitude of the mother to the oral health of her child ( $\mathrm{OR}=2.15,95 \% \mathrm{CI}=1.03-4.50)$; and the best socioeconomic position ( $\mathrm{OR}=2.68,95 \% \mathrm{CI}=1.36-5.31)$. Conclusions: The prevalence of visits to the dentist in the last year to receive professionally applied topical fluoride was very low (3.1\%). The results of the socioeconomic position suggest the existence of certain inequalities in oral health. It is necessary to implement policies and programs aimed at improving this scenario.
\end{abstract}

Keywords: oral health; health services; caries prevention; topical fluoride; Nicaragua

\section{Introduction}

Socioeconomic inequalities in health refer to the different health-related opportunities and resources that people of different social classes have, so that the most disadvantaged groups are in worse health than their better-positioned counterparts. These differences have their origin in the 
inequalities of the economic and social policies that exist in society [1]. In this sense, studies carried out in several countries around the world, both developed and developing, show the existence of socioeconomic inequalities in various aspects of health. It is observed that the socioeconomically disadvantaged population is generally the one with the lowest levels of health [2-4].

Dental caries continues to be one of the main oral health problems worldwide in school-aged children, and are concentrated in the most disadvantaged social groups [5]. Pitts et al. [6] mention that there are marked differences in caries-related health inequalities in developing and developed countries. Also, it is evident that there is a gradient in caries levels between the least developed and the most developed countries. According to epidemiological studies, in Nicaragua, the prevalence of dental caries in primary dentition is $77.7 \%$, with an average $\mathrm{dmft}$ (decayed, missing and filled teeth) index of $3.54 \pm 3.13$ for children 6 to 9 years of age [7]. In permanent dentition the prevalence is $37.9 \%$, with a mean DMFT (Decayed, Missing and Filled teeth) index of $0.98 \pm 1.74$ [8]. At the same time, it is observed that little more than $50 \%$ of caries lesions in the permanent dentition present treatment needs [9]. Likewise, there are differences between the different social groups, suggesting certain socioeconomic inequalities in oral health in the country. This disease represents a substantial burden both for health systems and for households, due to the costs required for their treatment; the more severe the lesion, the greater the technology and the resources required, so families often incur direct out-of-pocket expenses to obtain the needed services to maintain adequate oral health [10]. According to the World Health Organization, there is limited availability or inaccessibility of oral health services, which makes their utilisation rates particularly low among some vulnerable groups of the population. Moreover, it is estimated that in high-income countries, traditional curative dental care consumes between $5 \%$ and $10 \%$ of public health expenditure [11].

At the community level, as well as in clinical practice, one of the widely-used technologies to prevent and treat dental caries in its early stages is fluoride [12]; in addition, there are several modes available to provide it professionally, for example, varnish, gel, and fluoride solution [13-15]. In developed countries, the use of fluoride and gel varnish is common among dentistry professionals. The relatively high cost of professionally administered fluoridated agents and the shortage of dental labour, especially in low-income countries, have hindered the widespread adoption of these methods in public and private dental services [16]. In addition to this scenario, one of the most important barriers preventing people from going to health services is their economic type [17].

Recently, several studies have analysed the impact of the socioeconomic position on the oral health of the population, which is strongly determined by this variable, and is referred to as inequality in oral health. The exact path by which oral health or utilisation of oral health services and socioeconomic position are associated is still unclear. Likely mechanisms involve healthy behaviours, healthy lifestyles, and health care. In fact, the association between socioeconomic status and health is so strong that several researchers have hypothesised that social position may be the root cause of health [18]. Also, inadequate access to essential health services is one of the several determinants of social inequities in health. It may not be the major determinant, but it is important for the health sector to tackle directly [19]. The factors associated with the demand for professionally-applied topical fluoride (PATF) have been studied little, and in Nicaragua, there is no scientific antecedent of the subject. Studies in other countries have observed that the variables, associated with requests for dentist-administered PATF are: the best socioeconomic position [20,21], the greater frequency of dental brushing [20], the age of the children, greater parental knowledge about oral health, greater brushing frequency of parents, and access to some type of health insurance [21], among others. So, the objective of the present study is to determine the frequency of visits of Nicaraguan children to the dentist to receive PATF in the past year and the factors associated with these visits. 


\section{Materials and Methods}

\subsection{The Nicaraguan Health System Context}

Nicaragua, after Haiti, is the second poorest nation in the region. The General Health Law in Nicaragua establishes three pillars of the National Single Health System: the contributory, the non-contributory, and the voluntary. The System has public and private participation in the financing and provision of services, with little integration and articulation of the subsectors. The Ministry of Health (MINSA) is responsible for the Sectoral Rectory and is the primary service provider. The contributory scheme includes the Nicaraguan Social Security Institute (INSS), which administers, among other things, compulsory and optional health insurance for workers in the formal sector and their families, and the Ministries of Governance (MIGOB) and Defence (MIDEF) which cover their employees and their families. The non-contributory regime is in charge of the Ministry of Health and covers population groups without payment capacity. The voluntary scheme serves groups with payment capacity that purchase services with direct payment and the non-paying population within the non-profit private sector, which includes civil society and non-governmental organisations. Within the public sector, the Ministry of Health is the main provider. In 2008, the INSS covered $16.5 \%$ of the population; the MIGOB and the MIDEF 6\%; and the MINSA 61.2\%. The MINSA, the MIDEF, and the MIGOB have their own clinics and hospitals [22].

\subsection{Study Design and Sample Selection}

We used data from a cross-sectional study of which other aspects related to oral health were previously published [7-9,23]. The study universe consisted of 18,574 schoolchildren aged 6 to 12 years from elementary schools in the city of León, Nicaragua. Inclusion criteria were: (1) children apparently healthy aged 6 to 12 years; (2) enrolled in selected elementary schools; (3) whose parents gave informed consent for their children to participate in the study; and (4) who did not have fixed orthodontic appliances. Of the total number of existing schools in Leon, Nicaragua, through a simple random sampling, 25 schools were selected. Subsequently, using the sampling strategy proposed by the WHO [24], four boys and four girls from each of the seven age groups were included, which, in the end, resulted in 56 children from each of the 25 schools. The consent rate was $>90 \%$. In this way, they were similarly distributed by age and sex, which gave a final sample of 1400 schoolchildren.

\subsection{Variables and Data Collection}

The dependent variable was a visit to the dentist to receive PATF in the last year, which was dichotomised as (0) those who did not visit the dentist to receive PATF; and (1) those who did visit the dentist to receive PATF. The independent variables were collected through a questionnaire containing questions describing socioeconomic, sociodemographic, and behavioural variables. The variables included in the study were age, sex, birth order, and frequency of brushing; age, schooling, and occupation of the parents were also included, in addition to family size and the attitude of the mother toward oral health. The importance attributed by the mother to the oral health of the children was reduced to a positive attitude (1) if she answered "yes" to the following two questions: Do you consider it important that your child's teeth are kept in good condition? Have you ever examined your child's teeth to determine if they were healthy? A negative attitude (0) was registered if there was a "no" response to either of these two questions. This approach has been used in several studies $[25,26]$.

Indicators of socioeconomic position in the study. With the schooling and the occupation of both parents, two variables were established indicating socioeconomic position. For its construction, the analysis of principal components was used; specifically, that of polychoric correlation [27]. The two variables obtained in this way and related to each of these dimensions (schooling and occupation) were categorised into tertiles, where the first tertile refers to the worst socioeconomic position and the third tertile to the best. 


\subsection{Analysis of Data}

A univariate analysis was performed in which measures of central tendency and dispersion were calculated for the continuous variables. In the case of categorical variables, frequencies were obtained for each category, as well as the corresponding percentage. For the bivariate analysis, chi-square and Mann-Whitney tests were used according to the measurement scale of the variables to be tested.

In the multivariate model, binary logistic regression was used. For the construction of the final model, the steps marked by the literature were followed [28]. The final model included variables that had a value of $p<0.25$ in the bivariate analysis. An analysis of the variance inflation factor (VIF) was performed to detect and, if necessary, avoid multicollinearity between the independent variables. In both bivariate and multivariate analyses, the confidence intervals were calculated with robust standard errors (Huber-White errors), which accommodates accurate estimates even in cases of correlation by groups (schools). This is because the data observed were from children from different schools. Although this allows correlation within the same, it also suggests statistical independence between them. The program used for statistical procedures was STATA 11.0.

\subsection{Ethical Considerations}

This study was carried out according to the general health law in research and the scientific principles of the Declaration of Helsinki. Written consent was obtained from the parents/guardians of the participating children. The protocol was approved by the ethics committee review board of the Universidad Nacional Autónoma de Nicaragua (Campus León) and the Universidad Autónoma de Campeche (UAC/FO/MC-005), where one of the authors earned his Master of Science degree.

\section{Results}

In the study were included 702 boys and 698 girls with a mean age of $8.99 \pm 2.00$ years. The descriptive results are shown in Table 1. Most mothers demonstrated a positive attitude towards their children's oral health (57.1\%); the mean age of the mothers was $33.07 \pm 6.05$ years. The prevalence of visits to the dentist in the last year to receive PATF was 3.1\%.

Table 1. Descriptive results of study sample.

\begin{tabular}{lcc}
\hline \multicolumn{1}{c}{ Variable } & Frequency & Mean \pm SD; (Limits) \\
\hline Age & 1400 & $8.99 \pm 2.00 ;(6-12)$ \\
Mother's age & 1400 & $33.07 \pm 6.05 ;(20-52)$ \\
Family size (number of children) & 1400 & $3.12 \pm 1.58 ;(1-12)$ \\
& & Percentage \\
\hline Sex & & \\
\hline Men & 702 & 50.1 \\
Women & 698 & 48.8 \\
\hline Birth order & & 83.3 \\
\hline First to third & 1166 & 16.7 \\
$\quad$ Fourth or more & 234 & 42.9 \\
\hline Mother's attitude towards oral health & & 57.1 \\
\hline Negative & 600 & \\
Positive & 800 & 48.3 \\
\hline Frequency of tooth brushing & & 51.7 \\
\hline Less than 7 times/week & 676 & \\
At least 1 time per day & 724 & \\
\hline
\end{tabular}


Table 1. Cont.

\begin{tabular}{lcc}
\hline \multicolumn{1}{c}{ Variable } & Frequency & Mean \pm SD; (Limits) \\
\hline SEP (occupation) & & \\
\hline Low & 561 & 40.1 \\
Medium & 526 & 37.6 \\
High & 313 & 22.4 \\
\hline SEP (schooling) & & \\
\hline Low & 507 & 36.2 \\
Medium & 436 & 31.1 \\
High & 457 & 32.6 \\
\hline
\end{tabular}

Table 2 shows the results of the bivariate analysis. Statistically significant differences $(p<0.05)$ were observed through the categories of variables: sex, mother's attitude towards the child's oral health, dental brushing frequency, and socioeconomic position (scholarship).

Table 2. Bivariate results for visits to the dentist for PATF in children from 6 to 12 years of age.

\begin{tabular}{|c|c|c|c|}
\hline Variable & Without PATF & With PATF & $p$ Value \\
\hline Age & $8.99 \pm 2.00$ & $9.36 \pm 1.96$ & 0.2199 * \\
\hline Mother's age & $33.07 \pm 6.10$ & $32.98 \pm 5.11$ & 0.9083 * \\
\hline Family size (number of children) & $3.13 \pm 1.59$ & $2.72 \pm 1.18$ & 0.1080 * \\
\hline \multicolumn{4}{|l|}{ Sex } \\
\hline Men & $689(98.1)$ & $13(1.9)$ & \\
\hline Women & $667(95.6)$ & $31(4.4)$ & $0.005+$ \\
\hline \multicolumn{4}{|l|}{ Birth order } \\
\hline First to third & $1127(96.7)$ & $39(3.3)$ & \\
\hline Fourth or more & $229(97.9)$ & $5(2.1)$ & $0.334+$ \\
\hline \multicolumn{4}{|l|}{$\begin{array}{l}\text { Mother's attitude towards oral } \\
\text { health }\end{array}$} \\
\hline Negative & $589(98.2)$ & $11(1.8)$ & \\
\hline Positive & $767(95.9)$ & $33(4.1)$ & $0.015+$ \\
\hline \multicolumn{4}{|l|}{ Frequency of tooth brushing } \\
\hline Less than 7 times/week & $665(98.4)$ & $11(1.6)$ & \\
\hline At least 1 time per day & $691(95.4)$ & $33(4.6)$ & $0.002+$ \\
\hline \multicolumn{4}{|l|}{ SEP (occupation) } \\
\hline Low & $547(97.5)$ & $14(2.5)$ & \\
\hline Medium & $505(96.0)$ & $21(4.0)$ & \\
\hline High & $304(97.1)$ & $9(2.9)$ & $0.351+$ \\
\hline \multicolumn{4}{|l|}{ SEP (schooling) } \\
\hline Low & $498(98.2)$ & $9(1.8)$ & \\
\hline Medium & $426(97.7)$ & $10(2.3)$ & \\
\hline High & $432(94.5)$ & 25 (5.5) & $0.002+$ \\
\hline
\end{tabular}

* Mann-Whitney; + Chi-square.

In the multivariate model of binary logistic regression (Table 3), it was observed that women were more likely than men to have visits to the dentist in the last year to receive PATF (OR $=2.73$, $95 \% \mathrm{CI}=1.34-4.50$ ). The children of those mothers who had a positive attitude toward their child's oral health presented 2.5 times greater $(95 \% \mathrm{CI}=1.03-4.50)$ odds of visits to the dentist in the last year to receive PATF than those of mothers with negative attitudes. Finally, the best socioeconomic position 
$(\mathrm{OR}=2.68,95 \% \mathrm{CI}=1.36-5.31)$ increased the odds of having visits to the dentist in the last year to receive PATF.

Table 3. Multivariate logistic regression model for visits to the dentist in the last year by Nicaraguan schoolchildren to receive professionally applied topical fluoride.

\begin{tabular}{lccc}
\hline \multicolumn{1}{c}{ Variable } & OR & $\mathbf{9 5 \%}$ CI & $p$ Value \\
\hline Sex & & & \\
\hline $\begin{array}{l}\text { Men } \\
\text { Women }\end{array}$ & $1^{*}$ & & \\
\hline Mother's attitude towards oral health & 2.73 & $1.34-5.56$ & 0.006 \\
\hline $\begin{array}{l}\text { Negative } \\
\text { Positive }\end{array}$ & $1^{*}$ & & \\
\hline SEP (schooling) & 2.15 & $1.03-4.50$ & 0.042 \\
\hline $\begin{array}{l}\text { Low/Medium } \\
\text { High }\end{array}$ & $1{ }^{*}$ & & \\
\hline
\end{tabular}

* Reference category. Note: Model adjusted for the variables in the table as well as by age. $95 \%$ CI estimated with robust standard errors (cluster school). Goodness-of-fit test: Hosmer y Lemeshow: chi2 = 10.64, $p=0.2228$.

\section{Discussion}

In this study, we identified several variables associated with visits to the dentist in the last year to receive professionally applied topical fluoride; in addition, its prevalence was only $3.1 \%$, which could be considered low when it is known to be one of the most effective measures to reduce the prevalence of caries, especially in a developing country. In Nicaragua, as in other Latin American countries [29-33], oral health among school-age children shows unfavourable outcomes. There is a high prevalence of dental caries, high unmet oral health needs, and low experience of restorative treatment. Added to this scenario, as in other parts of the world [34], the use of preventive oral health services, in the application of PATF, is very low. In the world literature, very few studies have been done on the subject, since the majority are studies on the effectiveness of dental caries prevention. According to these studies, the work carried out in other countries indicates that the prevalence is between $5.1 \%$ and $11.5 \%$ [20,21], higher than that reported in the present study. Although there is no currently pure scientific consensus on the periodicity of visits to the dentist, the American Academy of Pediatrics and the American Academy of Pediatric Dentistry recommend the age of onset for the first consultation for a review of routine and to check the state of oral health of children by their first birthday, with subsequent periodic reviews at least twice a year. With these actions, the opportunity to perform both preventive and curative treatments of minimal invasion among children is increased [35,36]. On the other hand, a series of meta-analyses carried out by Marinho et al. on the application of fluoride in rinses [13], gel [14], and varnishes [15], conclude that there is clear evidence that the regular use of fluoride in one of these presentations has an effect on the reduction of caries in the primary and permanent dentition. Additionally, according to these recommendations, several studies have shown that regular care is associated with better oral health responses and a better quality of life [37,38].

Compared with men, women realise the greater use of health services. However, the increased use of health services by women is not a consistent finding, but depends, in part, on the type of service. Thus, women tend to use preventive and diagnostic services more frequently, while men make greater use of emergency services [39-41]. A similar pattern is observed in relation to oral health services [42]. In this sense, the results of the present study show that women also performed a higher percentage of visits to the dentist to receive PATF.

Other studies $[26,43,44]$ have observed that maternal characteristics are related to the use of oral health services. Specifically, the attitude of the mother to the oral health of her child has been pointed 
out by Andersen \& Davidson [45], who document the importance of attitudes toward health as strong predictors of the use of health services.

In the present study, we included several variables that theoretically determine the socioeconomic position. According to Galobardes et al. [46], schooling is an indicator of socioeconomic position that attempts to capture the stock of knowledge of a person. As formal education is usually completed in early adulthood and is strongly determined by the socioeconomic characteristics of parents, it can be conceptualised within the framework of the "life course." On the other hand, occupation is a measure of socioeconomic position that is frequently used, and represents the place of a person within society by income and intellect, as well as characterising the working relationships between employers and employees. The occupation of the "head of the household", or the "highest occupation within the household", can be used as a socioeconomic position indicator of dependents (e.g., spouse, children) or the house as a unit. Family size is a variable that has an influence on the socioeconomic position. Based on what Mechanic calls "competitive needs at home", the greater the number of individuals in the household, the greater the competition between them for family resources [47]. In our study, the variable that was related to visits to the dentist to receive PATF was schooling.

Despite the large number of studies that have addressed a range of social groups and health services (including preventive services), there is still little understanding of the underlying mechanisms that drive the persistence of socio-economic inequalities in the use of preventive services. Recently, the cultural capital of health and healthy lifestyles have been discussed theoretically concerning their role in health inequalities in the case of preventive care [48]. Specifically, inequalities in the use of preventive dental services have been observed in Spain [49] and, according to the present study, our results suggest the existence of inequalities in oral health.

The present analysis has limitations that must be considered for a better interpretation of the results. For example, the data are derived from a cross-sectional study, where the problem of temporal ambiguity is common, which refers to the measurement of cause and effect at the same time so those causal relationships cannot be established. Another limitation is that in retrospective studies, there is the possibility of introducing recall bias.

\section{Conclusions}

Based on the observed results, we can conclude that the prevalence of visits to the dentist in the last year to receive PATF was very low (only 3.1\%) when compared to the results obtained in other studies. It is known that PATF is one of the most effective measures to reduce the prevalence of caries, especially in a developing country. The results of the socioeconomic position suggest the existence of certain inequalities in oral health to this indicator. It is necessary to implement policies and programs aimed at improving this scenario.

Acknowledgments: This research was partially supported by a scholarship given to Miriam del Socorro Herrera by the Universidad Autónoma de Campeche and the Universidad Nacional Autónoma de Nicaragua-León. A grant to support fieldwork was received from the Switzerland Agency of Cooperation for Development (Styrelsen för Internationellt Utvecklingssamarbete). Publication supported by the Ministry of Education, Mexican Federal Government, through of The Faculty Development Program (PRODEP).

Author Contributions: Miriam del Socorro Herrera, Mirna Minaya-Sanchez, Alejandro Jose Casanova-Rosado, and Carlo Eduardo Medina-Solis were involved in the design and development of the study; Carlo Eduardo Medina-Solis designed the study, did the analysis of the data and wrote the first draft of the manuscript; America Patricia Pontigo-Loyola, Ruben de la Rosa-Santillana, Leticia Avila-Burgos, Rogelio Jose Scougall-Vilchis, and Sonia Marquez-Rodriguez were involved in the conception of the paper, analysis and interpretation of the results. All the authors were involved in the critical review and made intellectual contributions, they also accepted the final version.

Conflicts of Interest: The authors declare no conflicts of interest. 


\section{References}

1. Whitehead, M.; Dahlgren, G. Concepts and Principles for Tackling Social Inequities in Health; World Health Organization Regional Office for Europe: Copenhagen, Denmark, 2007.

2. Ruhe, A.K.; Wager, J.; Hirschfeld, G.; Zernikow, B. Household income determines access to specialized pediatric chronic pain treatment in Germany. BMC Health Serv. Res. 2016, 16, 140. [CrossRef] [PubMed]

3. Kim, S.; Hwang, J. Assessment of trends in socioeconomic inequalities in cancer screening services in Korea, 1998-2012. Int. J. Equity Health. 2016, 15, 30. [CrossRef] [PubMed]

4. Folb, N.; Bachmann, M.O.; Bateman, E.D.; Steyn, K.; Levitt, N.S.; Timmerman, V.; Lombard, C.; Gaziano, T.A.; Fairall, L.R. Socioeconomic and modifiable predictors of blood pressure control for hypertension in primary care attenders in the Western Cape, South Africa. S. Afr. Med. J. 2016, 106, 1241-1246. [CrossRef] [PubMed]

5. Schwendicke, F.; Dörfer, C.E.; Schlattmann, P.; Foster-Page, L.; Thomson, W.M.; Paris, S. Socioeconomic inequality and caries: A systematic review and meta-analysis. J. Dent. Res. 2015, 94, 10-18. [CrossRef] [PubMed]

6. $\quad$ Pitts, N.; Amaechi, B.; Niederman, R.; Acevedo, A.M.; Vianna, R.; Ganss, C.; Ismail, A.; Honkala, E. Global Oral Health Inequalities: Dental Caries Task Group-Research Agenda. Adv. Dent. Res. 2011, 23, 211-220. [CrossRef] [PubMed]

7. Herrera, M.S.; Medina-Solís, C.E.; Minaya-Sánchez, M.; Pontigo-Loyola, A.P.; Villalobos-Rodelo, J.J.; Islas-Granillo, H.; de la Rosa-Santillana, R.; Maupomé, G. Dental plaque, preventive care, and tooth brushing associated with dental caries in primary teeth in schoolchildren ages 6-9 years of Leon, Nicaragua. Med. Sci. Monit. 2013, 19, 1019-1026.

8. Herrera, M.S.; Medina-Solís, C.E.; Islas-Granillo, H.; Lara-Carrillo, E.; Scougall-Vilchis, R.J.; Escoffié-Ramírez, M.; De la Rosa-Santillana, R.; Avila-Burgos, L. Sociodemographic, socio-economic, clinical and behavioural factors modifying experience and prevalence of dental caries in the permanent dentition. West Indian Med. J. 2014, 63, 752-757. [CrossRef] [PubMed]

9. Herrera, M.S.; Medina-Solís, C.E.; Avila-Burgos, L.; Robles-Bermeo, N.L.; Lara-Carrillo, E.; Lucas-Rincón, S.E.; Marquez-Corona, M.L.; Villalobos-Rodelo, J.J. Treatment needs for dental caries and restorative care index on the permanent dentition of Nicaraguan children. West Indian Med. J. 2017. [CrossRef] [PubMed]

10. García-Cortés, J.O.; Mejia-Cruz, J.A.; Medina-Cerda, E.; Orozco-De la Torre, G.; Medina-Solís, C.E.; Márquez-Rodriguez, S.; Marquez-Rodriguez, S.; Navarrete-Hernandez, J.J.; Islas-Granillo, H. Experiencia, prevalencia, severidad, necesidades de tratamiento para caries dental e índice de cuidados en adolescentes y adultos jóvenes mexicanos. Rev. Investig. Clin. 2014, 66, 581-588.

11. Organización Mundial de la Salud. Salud Bucodental. Nota Informativa 318. 2012. Available online: http:/ / www.who.int/mediacentre/factsheets/fs318/es/ (accessed on 18 September 2016).

12. Eklund, S.A.; Pittman, J.L.; Heller, K.E. Professionally applied topical fluoride and restorative care in insured children. J. Public Health Dent. 2000, 60, 33-38. [CrossRef] [PubMed]

13. Marinho, V.C.; Chong, L.Y.; Worthington, H.V.; Walsh, T. Fluoride mouthrinses for preventing dental caries in children and adolescents. Cochrane Database Syst. Rev. 2016, 7, CD002284. [PubMed]

14. Marinho, V.C.; Worthington, H.V.; Walsh, T.; Chong, L.Y. Fluoride gels for preventing dental caries in children and adolescents. Cochrane Database Syst. Rev. 2015, 6, CD002280.

15. Marinho, V.C.; Worthington, H.V.; Walsh, T.; Clarkson, J.E. Fluoride varnishes for preventing dental caries in children and adolescents. Cochrane Database Syst. Rev. 2013, 7, CD002279.

16. Lo, E.C.; Tenuta, L.M.; Fox, C.H. Use of professionally administered topical fluorides in Asia. Adv. Dent. Res. 2012, 24, 11-15. [CrossRef] [PubMed]

17. Jiménez-Gayosso, S.I.; Medina-Solís, C.E.; Lara-Carrillo, E.; Scougal-Vilchis, R.J.; de la Rosa-Santillana, R.; Márquez-Rodríguez, S.; Mendoza-Rodriguez, M.; Navarrete-Hernandez Jde, J. Socioeconomic inequalities in oral health service utilization any time in their lives for Mexican schoolchildren from 6 to 12 years old. Gac. Med. Mex. 2015, 151, 27-33. [PubMed]

18. Laaksonen, M.; Rahkonen, O.; Martikainen, P.; Lahelma, E. Socioeconomic position and self-rated health: The contribution of childhood socioeconomic circumstances, adult socioeconomic status, and material resources. Am. J. Public Health 2005, 95, 1403-1409. [CrossRef] [PubMed]

19. Chauvel, L.; Leist, A.K. Socioeconomic hierarchy and health gradient in Europe: The role of income inequality and of social origins. Int. J. Equity Health 2015, 14, 132. [CrossRef] [PubMed] 
20. Casanova-Rosado, A.J.; Medina-Solís, C.E.; Casanova-Rosado, J.F.; Avila-Burgos, L.; Vallejos-Sánchez, A.A.; Márquez-Rodríguez, S.; Marquez-Corona, M.L.; Maupome, G. Socio-economic inequality in professionally administered topical fluoride among Mexican school children. West Indian Med. J. 2017. [CrossRef]

21. Ceron-Zamora, E. Factors Associated with the Use of Oral Health Services to Receive Topical Application of Fluoride by a Dentist in Schoolchildren Aged 6 to 12 Years; Working Paper; Universidad Autónoma del Estado de Hidalgo: Pachuca de Soto, Mexico, 2016.

22. Muiser, J.; Sáenz, M.R.; Bermúdez, J.L. Health system of Nicaragua. Salud Publica Mex. 2011, 53 (Suppl. 2), S233-S242. [PubMed]

23. Herrera, M.S.; Medina-Solís, C.E.; Robles-Bermeo, N.L.; Lara-Carrillo, E.; Guadarrama-Quiroz, L.J.; Navarrete-Hernández, J.J.; Villalobos-Rodelo, J.J.; Pontigo-Loyola, A.P. Indicators of oral hygiene and preventive dental care as variables associated with the high severity of caries. West Indian Med. J. 2017. [CrossRef]

24. WHO. Chapter 1: Organization of a basic oral health survey. In Oral Health Survey-Basic Methods, 4th ed.; World Health Organization: Geneva, Switzerland, 1997; pp. 4-9.

25. Vallejos-Sánchez, A.A.; Medina-Solis, C.E.; Maupomé, G.; Casanova Rosado, J.F.; Minaya-Sánchez, M.; Villalobos-Rodelo, J.J.; Pontigo-Loyola, A.P. Socio-behavioral factors influencing tooth brushing frequency in schoolchildren. J. Am. Dent. Assoc. 2008, 139, 743-749. [CrossRef] [PubMed]

26. Vallejos-Sánchez, A.A.; Medina-Solís, C.E.; Minaya-Sánchez, M.; Villalobos-Rodelo, J.J.; Marquez-Corona, M.L.; Islas-Granillo, H.; Maupome, G. Maternal characteristics and treatment needs as predictors of dental health services utilization among Mexican school children. Eur. J. Paediatr. Dent. 2012, 13, 307-310. [PubMed]

27. Kolenikov, S.; Ángeles, G. The Use of Discrete Data in Principal Component Analysis with Applications to Socio-Economic Indices; CPC/MEASURE Working Paper No. WP-04-85; MEASURE Evaluation: Chapel Hill, NC, USA, 2004.

28. Bagley, S.C.; White, H.; Golomb, B.A. Logistic regression in the medical literature: Standards for use and reporting, with particular attention to one medical domain. J. Clin. Epidemiol. 2001, 54, 979-985. [CrossRef]

29. Llompart, G.; Marin, G.H.; Silberman, M.; Merlo, I.; Zurriaga, O.; GIS (Grupo Interdisciplinario para Salud). Oral health in 6-year-old schoolchildren from Berisso, Argentina: Falling far short of WHO goals. Med. Oral Patol. Oral Cir. Bucal. 2010, 15, e101-5. [CrossRef] [PubMed]

30. Tellez, M.; Santamaria, R.M.; Gomez, J.; Martignon, S. Dental fluorosis, dental caries, and quality of life factors among schoolchildren in a Colombian fluorotic area. Community Dent. Health 2012, 29, 95-99. [PubMed]

31. Molina-Frechero, N.; Durán-Merino, D.; Castañeda-Castaneira, E.; Juárez-López, M.L. Dental caries experience and its relation to oral hygiene in Mexican children. Gac. Med. Mex. 2015, 151, 485-490. [PubMed]

32. Peres, M.A.; Sheiham, A.; Liu, P.; Demarco, F.F.; Silva, A.E.; Assunção, M.C.; Menezes, A.M.; Barros, F.C.; Peres, K.G. Sugar Consumption and Changes in Dental Caries from Childhood to Adolescence. J. Dent. Res. 2016, 95, 388-394. [CrossRef] [PubMed]

33. Ferreira-Gaona, M.I.; Diaz-Reissner, C.V.; Pérez-Bejarano, N.M.; Sanabria-Vázquez, D.A.; Alvarenga-Rodas, M.V.; Diosnel-Bazán, D. Oral health in preschoolers and level of knowledge about oral hygiene of their mothers, in public and private schools in San Lorenzo, Paraguay. Pediatria 2016, 43, 129-136.

34. AlMutairi, M.A. Parents' satisfaction with pediatric dental care provided by dental college, Riyadh. J. Int. Soc. Prev. Community Dent. 2016, 6, 542-548. [CrossRef] [PubMed]

35. American Academy of Pediatric Dentistry, Council on Clinical Affairs. Policy on the Dental Home. 2010. Available online: www.aapd.org/media/Policies_Guidelines/P_DentalHome.pdf (accessed on 12 July 2011).

36. American Academy of Pediatrics. Oral health risk assessment timing and establishment of the dental home. AAP Policy Statement. Pediatrics 2003, 111, 1113-1116.

37. Listl, S.; Moeller, J.; Manski, R. A multi-country comparison of reasons for dental non-attendance. Eur. J. Oral Sci. 2014, 122, 62-69. [CrossRef] [PubMed]

38. Harris, R.V.; Pennington, A.; Whitehead, M. Preventive dental visiting: A critical interpretive synthesis of theory explaining how inequalities arise. Community Dent. Oral Epidemiol. 2017, 45, 120-134. [CrossRef] [PubMed] 
39. Redondo-Sendino, A.; Guallar-Castillón, P.; Banegas, J.R.; Rodríguez-Artalejo, F. Gender differences in the utilization of health-care services among the older adult population of Spain. BMC Public Health 2006, 6, 155. [CrossRef] [PubMed]

40. Carretero, M.T.; Calderón-Larrañaga, A.; Poblador-Plou, B.; Prados-Torres, A. Primary health care use from the perspective of gender and morbidity burden. BMC Womens Health 2014, 14, 145. [CrossRef] [PubMed]

41. Boccolini, C.S.; de Souza Junior, P.R.B. Inequities in Healthcare utilization: Results of the Brazilian National Health Survey, 2013. Int. J. Equity Health 2016, 15, 150. [CrossRef] [PubMed]

42. Yu, S.M.; Bellamy, H.A.; Schwalberg, R.H.; Drum, M.A. Factors associated with use of preventive dental and health services among U.S. adolescents. J. Adolesc. Health 2001, 29, 395-405. [CrossRef]

43. Medina-Solís, C.E.; Maupomé, G.; Avila-Burgos, L.; Hijar-Medina, M.; Segovia-Villanueva, A.; Pérez-Núñez, R. Factors influencing the use of dental health services by preschool children in Mexico. Pediatr. Dent. 2006, 28, 285-292. [PubMed]

44. Goettems, M.L.; Ardenghi, T.M.; Demarco, F.F.; Romano, A.R.; Torriani, D.D. Children's use of dental services: Influence of maternal dental anxiety, attendance pattern, and perception of children's quality of life. Community Dent. Oral Epidemiol. 2012, 40, 451-458. [CrossRef] [PubMed]

45. Andersen, R.; Davidson, P.L. Improving access to care in America: Individual and contextual indicators. In Changing the U.S. Health Care System: Key Issues in Health Services Policy and Management, 3rd ed.; Andersen, R.M., Rice, T.H., Kominski, G.F., Eds.; Jossey-Bass: San Francisco, CA, USA, 2007; pp. 3-31.

46. Galobardes, B.; Shaw, M.; Lawlor, D.A.; Lynch, J.W.; Davey-Smith, G. Indicators of socioeconomic position (part 1). J. Epidemiol. Community Health 2006, 60, 7-12. [CrossRef] [PubMed]

47. Mechanic, D. Medical Sociology: A Comprehensive Text; Free Press: New York, NY, USA, 1978.

48. Missinne, S. Moving Towards a Better Understanding of Socioeconomic Inequalities in Preventive Health Care Use: A Life Course Perspective. In A Life Course Perspective on Health Trajectories and Transitions; Burton-Jeangros, C., Cullati, S., Sacker, A., Blane, D., Eds.; Springer: Cham, Switzerland, 2015; Chapter 6.

49. Garrido-Cumbrera, M.; Borrell, C.; Palència, L.; Espelt, A.; Rodríguez-Sanz, M.; Pasarín, M.I.; Kunst, A. Social class inequalities in the utilization of health care and preventive services in Spain, a country with a national health system. Int. J. Health Serv. 2010, 40, 525-542. [CrossRef] [PubMed] 